\title{
Domenico Scarlatti e a Cultura Portuguesa
}

\section{Humberto d'Ávila}

Não podia dar-me mais satisfação e conforto ler, na "Abertu$\mathrm{ra}^{\prime}$ desta revista, a posição expendida por François Lesure, o abalisado diretor de estudos da École des Hautes Études, da Sorbonne (Paris), de que a prioridade da musicologia, em cada país, deve ser dada às raízes e caminhos da própria música, de preferência a tentar" descobrir a verdadeira ideologia do Ring ou, entào, a tratar uma vez mais da origem da forma-sonata". E acrescenta o antigo chefe do Departamento de Música da Biblioteca Nacional francesa, exortando diretamente o Brasil, que se "espera um recenseamento exaustivo das obras que subsistem desde a época colonial, situando a natureza da sua escrita; dispor de estudos aprofundados concernentes as atividades dos concertos no século XIX; verificar as influências que foram exercidas no desenvolvimento do ensino, formaçảo de um público e as premissas duma crítica musical específica (...) As questoes sào numerosas, necessitando mais acentuadamente de pesquisas em arquivos locais, correspondência existente e informaçòes da imprensa da época".

Estas palavras só não são proféticas em relaçào a Portugal por virem a posteriori. Sảo de 1990 e exprimem uma orientação que, embora traduza uma idéia geral em curso na musicologia contemporânea, já estava a ser aplicada institucionalmente, em Portugal, desde 1976. Outro não foi o espírito que levou à criação, pelo signatário, dum serviço de musicologia no organismo estatal competente na área do patrimônio cultural. 
Preenchendo um vazio na Administração pública, que possibilitara a dispersão, o extravio e a perda de inumeráveis e valiosos manuscritos, instrumentos e toda a classe de documentos auxiliares da história, o novo serviço guiou-se logo de início por uma idéia principal: rastrear, recuperar e classificar o mais possivel tudo o que representasse qualquer contribuição para o enriquecimento do acervo repertorial, ou para o melhor conhecimento da história da música em Portugal, e se encontrasse ainda fora do circuito organizado dos arquivos, bibliotecas e museus nacionais. A sua tarefa consistiu numa espécie de trabalho arqueológico: tal como para este tudo importa - uma esquírola óssea, um caco de barro, um fragmento de metal ou as pedras dum antigo castrejo -, também na missão que o referido departamento a si próprio impôs todo o vestígio do novo passado musical era encarado com igual interesse, desde a página solta duma partitura original, testemunho da criatividade artística dum ignoto anônimo, a um cartão de visita, a um anúncio de liçōes, com a indicação do preço, ou a cartas avulsas, que conservam simples dados cronológicos ou impressões colhidas ao vivo, sem deixar, no mesmo lote, programas de concertos idos, desenhos e velhas fotografias, utensílios de uso pessoal, etc. Mas enquanto, no caso do arqueólogo, o material reunido é o seu objeto de estudo, ali o que se visava era, com a humildade que compete a um serviço público, salvar o que estava em risco de desaparecer, inventariar, para encorporá-lo no patrimônio da nação, e criar as condições para que esse repositório fosse colocado, da melhor maneira, ao dispor de todos. A safra foi copiosa e reveladora de quanto sobreviveu à devastação dos tempos, num terreno que, comprovando a existência duma profusa atividade e duma extensa tradição, se encontrava praticamente inexplorado, bastardo de qualquer ação sistemática de prospecção sob chancela oficial. Em alfarrabistas, lojas de livros antigos, ferro-velhos, armazéns de papel, casas de antigüidades e residências particulares ou na posse de artistas ou dos seus herdeiros, começou-se a descobrir um espólio vastíssimo e percentualmente significativo. Ofertas, propostas, pistas e avisos choviam e, a breve trecho, 
tinha-se acumulado uma enorme massa de muitos milhares de documentos, ou afins, de diversa ordem. Só partituras manuscritas dos séculos XVIII e XIX, principalmente, ascendem a mais de 20.000. Por vezes, partes soltas permitiam completar obras que jazem truncadas nos arquivos. Alguns instrumentos preciosos de feitura portuguesa foram entretanto resgatados, um deles na Alemanha, e iniciou-se, paralelamente, uma campanha de restauro de órgãos históricos pilhados ou em degradaçào na maioria das igrejas. Os resultados favoráveis obtidos chegaram a fazer pensar na criação dum organismo autônomo que proporcionasse tanto ao ivestigador como ao público interessado a apreciação em conjunto, num mesmo local, dum determinado problema musicológico, quer peia consulta de livros e documentos, quer pela observação das peças organológicas concernentes a uma época dada, quer, ainda, pela ilustração iconográfica, quer, finalmente, pela experimentação ao piano de composições do seu interesse ou pela sua escuta fonográfica, caso houvesse as gravações respectivas. Esta gama de possibilidades constituiria, igualmente, para o artista intérprete desejoso de renovar o seu repertório, uma fonte de sugestões permanente. Por motivos políticos, por incompreensão do seu alcance, por ignorância, no final de contas, o projeto, apenas encetado, não foi por diante. Ficou uma grande frustração, mas também o conforto de se ter colocado sob abrigo e recuperado para a ciência e para a arte coleçōes que, na situação de abandono em que estavam, corriam o risco de, mais tarde ou mais cedo, acabarem por desaparecer como, anteriormente, tantas outras.

Ora, entre os muitos espólios recolhidos, acha-se o histórico arquivo musical do conde de Redondo, D. Fernando de Sousa Coutinho (séc. XIX), esclarecido melômano e amador, que mantinha em casa, com a família, os amigos e até os criados uma pequena orquestra e, mesmo eventualmente, um coro para a execução de obras tanto religiosas, na sua capela, como profanas, nos seus salóes. Quis o acaso, talvez para confirmar o acerto da ação empreendida, que do numeroso acervo constasse um livro, magnificamente encadernado e de primorosa caligrafia, com este título: 
Libro di Tocate /Per Cembalo, e/Tutti / Del Sig ${ }^{\text {re }}$ Cavaliero / D. Domenico Scarlatti. Era, obviamente, uma seleção de peças de cravo da autoria do compositor napolitano, que, como se sabe, viveu alguns anos em Lisboa no reinado de D. João V, indo morrer em Madrid aonde acompanhou a sua real e talentosa discípula D. Maria Bárbara de Bragança, quando do casamento desta com Fernando VI de Espanha. A coletânea, por razōes deduzíveis, deve ter sido elaborada para fornecer música nova à corte lisboeta, onde o autor continuava a ser muito apreciado, e enviada de Madrid. O conde de Redondo, pela sua fortuna e relações com o meio musical, pôde dar-se ao gosto de reunir uma notável coleção de partituras, grande parte autógrafas; a sua posição na corte ter-lhe-á proporcionado um dia o acesso à preciosa coletânea scarlattiana, uma jóia a valorizar o conjunto. Mas estava ele longe, nesse tempo, de avaliar todo o significado do volume.

$\mathrm{O}$ meu imediato cuidado, ao deparar-se-me o exemplar, foi o de providenciar no sentido de que se procedesse ao cotejo do incipit de cada peça com o das Sonatas reconhecidas do mestre napolitano, tarefa em que contei com dois creditados colaboradores: o sábio professor Santiago Kastner e o jovem musicólogo João Azevedo, hoje bibliotecário do Teatro Nacional de S. Carlos, a Ópera de Lisboa. O primeiro, consultando os inventários existentes (Longo, Kirkpatrick, etc.) e valendo-se dos seus contactos junto de arquivos italianos, espanhóis e outros, chegou a esta conclusão surpreendente: de todas as sonatas compiladas, uma havia, a $\mathrm{n}^{\circ} 25$ da série, que não coincidia com qualquer outra, era desconhecida e podia, pois, considerar-se inédita. O segundo, que fazia então em Kassel (RFA) um estágio na Redação do RISM (Répertoire International des Sources Musicales), confirmou no computador central da organização que nenhum incipit de peças scarlattianas conservadas em qualquer parte do Mundo correspondia ao fornecido. O achado era de festejar, pois se verificava no próprio ano de 1985, o dos centenários do nascimento de Bach, Händel e Scarlatti. Numa conferência de imprensa, realizada no Instituto Português do Patrimônio Cultural, em junho (V. Diário de Notícias, Lisboa, 
de 20 desse mês e ano), coube-me assim o privilégio de anunciar ao Mundo a boa nova, como a contribuição de Portugal às comemorações a decorrer. Não podia ela ser melhor - e o fato só por si justificava a razão de ser do Departamento de Musicologia daquele organismo e coroava de êxito a sua política.

Esta é a história recente da compilação que o professor Gerhard Doderer, do Departamento de Ciencias Musicais da Universidade Nova de Lisboa, tomou a iniciativa de publicar numa excelente edição fac-similada do Instituto Nacional de Investigação Científica (1991), antecedida dum importante estudo daquele musicólogo, ornada dalgumas estampas e acompanhada dum disco compacto com a interpretação de treze sonatas, entre elas a $\mathrm{n}^{\circ} 25$, pela cravista Cremilde Rosado Fernandes num instrumento português do século XVIII.

O estudo é importante por, além da matéria de análise do manuscrito, aproveitar ao professor Doderer para revelar o resultado das suas investigações numa fonte ainda não explorada neste aspecto (Vaticano, Arquivio Segreto. Secretaria di Stato-Portogallo). A entrada de Scarlatti na capital portuguesa estava até agora envolta em dúvidas e controvérsias. Um dos relatórios periódicos de Mons. Vicente Bicchi, núncio apostólico, consigna a data exata da chegada do compositor, por via terrestre: 29 de novembro de 1719. Este é, daqui em diante, um dado adquirido, que não se pode ignorar e põe cobro a mais conjeturas dos historiadores. A sua estada em Lisboa não foi porém contínua, o que aliás se sabia, mas as duas interrupções efetuadas, ambas por deslocações a Roma, estão delimitadas com mais certeza: uma deu-se de 1724 a 1725 , localizando-se em $1^{\circ}$ de janeiro de 1726 o recomeço das atividades do músico na capela real; a outra, por motivo do seu casamento, decorreu entre 28 de janeiro do ano seguinte e 27 de dezembro de 1729 , para logo se seguir a viagem na comitiva de D. Maria Bárbara, a caminho de Sevilha. O signatário, que fez parte da comissão nacional das comemorações scarlattianas, só tem que congratular-se com a eliminação dum escolho com que ele próprio se debateu. 


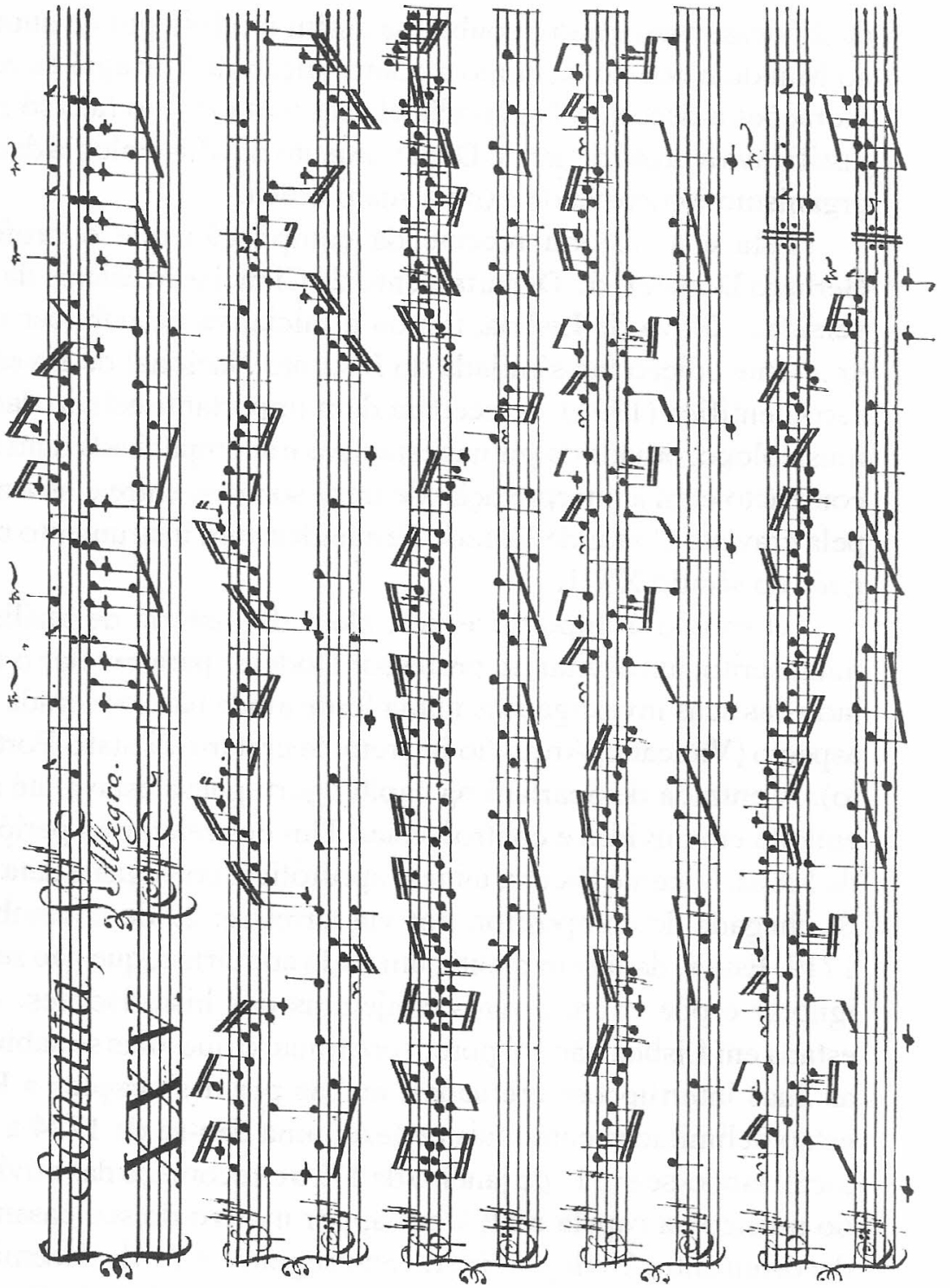




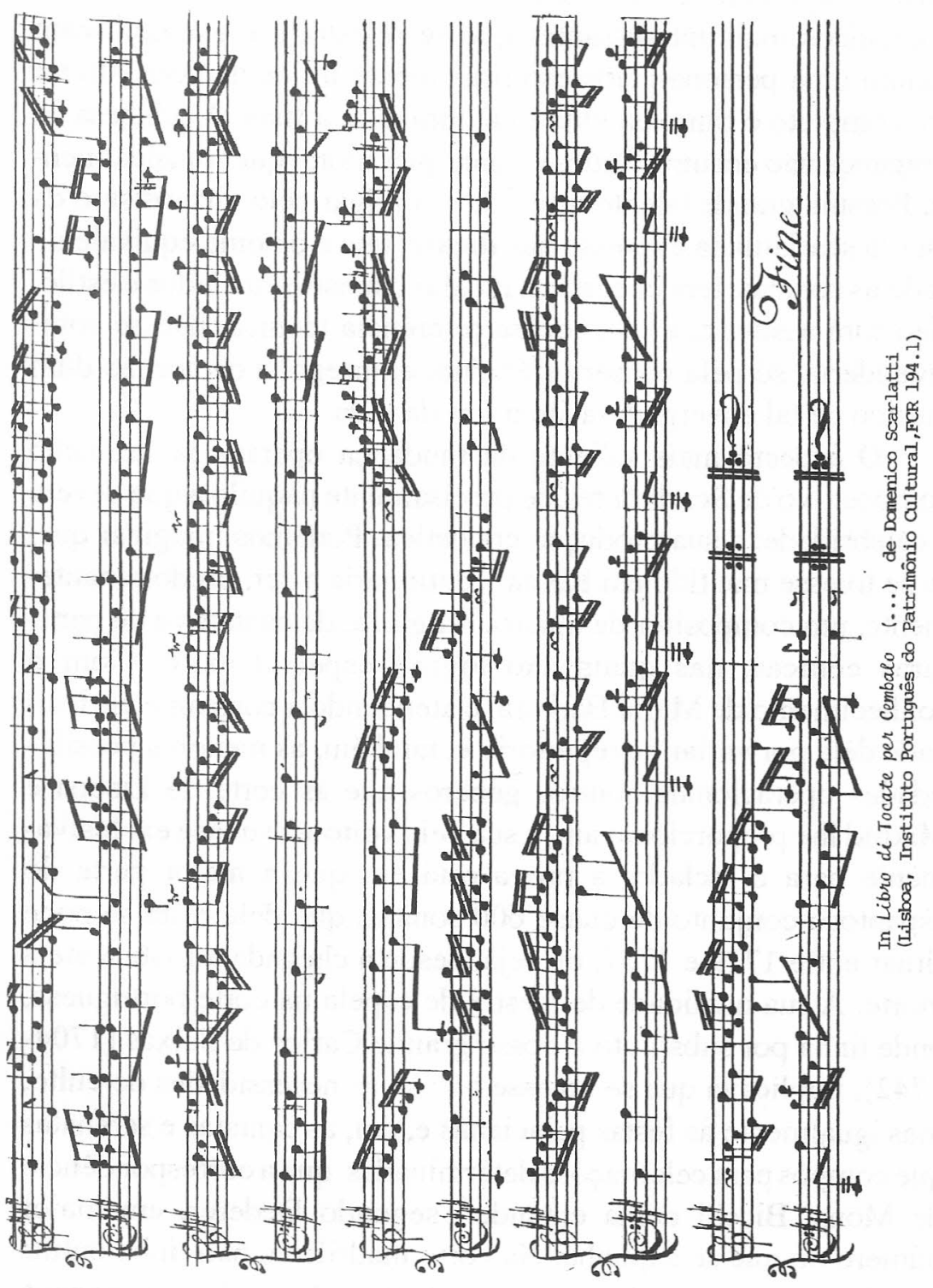


As relações de amizade, admiração e consideração recíproca entre o napolitano e a sua discípula é um dos episódios humanos e artísticos mais interessantes que se registram e exemplificam quanto uma personalidade espiritualmente influente pode alterar por completo o rumo da vida e da obra dum artista. A princesa de Bragança não era uma figura vulgar, quer moral quer musicalmente. Possuía grande talento artístico e, a julgar pelo virtuosismo da escrita scarlattiana expresso nas tocate, que é o nome equivalente dado às sonatas, terá chegado a igualar o mestre em dedos e estilo. Não fora assim, e, a mais dessa referência técnica, não se compreenderia, só pela conservação dum emprego, a dedicação dum músico de tal envergadura até o fím da vida.

$\mathrm{O}$ aspecto mais saliente da mudança operada no trabalho compositivo de Scarlatti reside precisamente naquilo a que deverá a celebridade: a sua produção cravística. Podemos imaginar que, se se tivesse mantido em Roma, continuaria a ser, predominantemente, um compositor de música religiosa, de cantatas e de partituras cênicas, nas quais não logrou especial êxito. Com o conhecimento de Maria Bárbara, e atendendo à constante curiosidade dela por variar de repertório e, também, às menores possibilidades operacionais noutros gêneros que as corte de Lisboa e Madrid lhe proporcionavam, a sua veia voltou-se quase exclusivamente para o teclado: a prova está em que a maior parte do espantoso conjunto de quase 600 sonatas que dele resta se pode situar entre 1719 e 1757, ou seja, desde a chegada a Lisboa até a morte. A sua qualidade de mestre de capela na corte portuguesa, onde tinha por substituto o nosso grande Carlos de Seixas (17041742), implicava que se votasse não só às necessidades do culto, mas igualmente às festas palacianas e, dai, as cantatas e serenatas que compôs para celebrações determinadas, que a correspondência de Mons. Bicchi deixa entender, segundo Dederer, em maior número do que se supunha. Na corte madrilena, não tinha outras funçōes e é curioso observar que o famoso Farinelli, que gozava do máximo poder nos meios cortesãos e bem o conhecia, tendo-lhe valido financeiramente em situações de apuro por dívidas de jogo, 
nunca se lembrasse dele ao organizar as suas faustosas temporadas de ópera italiana.

O Libro di Tocate per Cembalo do IPPC (FCR 194.1), onde se copiam 60 sonatas, é por si mesmo um exemplar único no espólio do compositor e até agora desconhecido; ademais da inclusāo da sonata inédita, na tonalidade de lá maior, preferida do autor, contém outras informaçōes que acrescentam o seu valor documental, não obstante as restantes peças da coletânea serem, com variantes em certos casos, as recenseadas noutras partes. Naturalmente que a ordem das sonatas aqui é diferente da numeração de Kirkpatrick, mas, confrontando-as, nem sempre conferem em alguns elementos, oferecendo as de Lisboa indicações de andamento que permitem corrigir ou completar as versōes correntes. Por exemplo: o Non Presto de K. 118 é Allegro em Lisboa, como igualmente o é a K. 125, marcada Vivo. Acontece haver sonatas de Lisboa omissas quanto a andamento, o que se pode suprir, por sua vez, graças aos manuscritos de Veneza e Parma, como fez Kirkpatrick, mas o contrário também se dá e a K. 145, sem qualquer indicação, pode agora regular-se pela sua equivalente Lx. 36, rubricada $\mathbf{A l l}^{\mathbf{0}}$ non Presto. Na maioria dos casos, coincidem porém. Relativamente a esta última sonata, de cuja autoria se duvidava, o manuscrito FCR 194.1 (IPPC) vem confirmar a única cópia em que aparecia até aqui (Cambridge, Fitzwilliam Museum), como sendo na verdade de Scarlatti. Ressalta ainda da observação das peças do manuscrito de Lisboa, como sublinha G. Doderer, a estrutura de um só andamento bipartido, e, por vezes, o emparelhamento de sonatas que nas demais versões figuram independentes. Outros aspectos, como a repetição de compassos, duplicaçào de notas, etc., recomendam por parte do estudioso e do executante-intérprete uma consulta atenta desta ediçāo fac-similada.

Baseando-se na extensào dos instrumentos ibéricos, o prof. Doderer entrega-se a seguir a uma análise das partituras, com intenção de averiguar os períodos de criação. A maioria dos manuscritos de Veneza e Parma correspondentes às composições 
do nosso livro está assinalada com os anos 1742 e 1749, muito depois da saída do músico de Lisboa, o que é natural. Algumas poderão ser mesmo posteriores. O âmbito normal dos cravos portugueses na altura da estada do compositor em Portugal era de Dó-ré " ou Dó-mi "" (51 e 53 teclas) e isso caracterizaria cronologicamente as sonatas compostas em Lisboa. Absolutizando este método, J. H. van der Meer havia proposto uma classificação da obra de Scarlatti por períodos organológicos, que refletem a evolução crescente do número de teclas. É evidente que uma peça com extensão grande (que chega, passado 1750, ao âmbito Sol 1 a sol ${ }^{\prime \prime}=61$ teclas) não pode ter sido concebida para instrumento mais reduzido. Mas o contrário é possível: o fato de se ter à disposição uma orquestra sinfônica nào impede que se escreva para conjunto de câmara ... D. Maria Bárbara possuía em Madrid instrumentos de várias dimensões, o que daria plena liberdade de inspiração ao seu compositor, e só a circunstância de a maior parte das peças da coletânea do conde de Redondo ser de âmbito alargado pode, com efeito, autorizar a conclusão de que o manuscrito Lx. 194.1 não terá sido organizado "antes de meados dos anos de setecentos", tanto mais que "apenas uma parte das peças desse manuscrito poderá ser executada em instrumentos portugueses" disponíveis no período lisboeta de Scarlatti. Quanto me parece, somente critérios estilísticos e morfológicos permitirão destrinçar o já velho problema da cronologia das sonatas.

No que tange a Portugal, a exclusão das de maior extensão circunscreve o campo de observação, no qual entram, por sua vez, as características especiais de construção do cravo e do piano de martelos portugueses, que os distinguem dos seus congêneres doutros países europeus (a este propósito, o prof. Doderer nào deixa de apontar Lisboa como "o palco de passagem do cravo para o pianoforte").

Devem-se a este musicólogo, e a alguns outros estrangeiros, como o citado van der Meer, as mais recentes investigaçòes sobre a natureza acústica e factual dos instrumentos portugueses, quer no respeitante ao temperamento musical quer as particularidades 
de fabrico, que condicionaram de modo peculiar a criação sonora nesta faixa da Península Ibérica. Doderer enumera, em pormenor, essas particularidades, denunciativas duma "tradicional e autônoma maneira de construir instrumentos de tecla e corda no Portugal setecentista" e de que temos por relevantes o tipo de madeiras nacionais utilizadas nas diversas partes, o corpo mais alongado por meio da duplicação do segmento vibratório das cordas de oitava a oitava, a colocação de réguas e ilhargas, a forma do cavalete em $\mathrm{S}$, a disposição de dois registros de 8 pés e o emprego do latão no encordoamento.

De tudo isto, o que, no entanto, pode ter mais interesse para o artista, para o crítico, e afinal para o público, é o seu resultado estético, que deve ser tido em conta, modernamente, na conceptualização da linguagem de Scarlatti - aquela que ele havia em mente como conseqüência da sua conversão auditiva aos novos meios. Essa sensação de autenticidade, que tanto domina as preocupações atuais de reconstituição erudita da música antiga, é-nos fornecida, com o volume em apreço, no registro sonoro, que o acompanha, dum instrumento bem representativo genuíno da arte portuguesa: o cravo de Joaquim José Antunes (Dó-mi " "'), datado de Lisboa 1758 (IPPC, MIC 372). Também nisto se torna notado o mérito do Departamento de Musicologia, que tinha a seu cargo a valiosa coleçào nacional de instrumentos musicais antigos, ao promover em 1986 o seu-restauro, reconhecido o alcance da proposta da conceituada Casa Neupert, de Bamberga (RFA), para, com todas as garantias, o fazer a troco de autorização para a sua cópia comercial. Tal acordo, susceptivel de proporcionar a difusão no Mundo dum produto típico da cultura portuguesa, possibilita hoje a todos os interessados a posse duma réplica dum tão famoso cravo dessa origem. O mais impressionante na audição que o disco nos oferece, nào sem a consciência de que a recebemos filtrada pelo requinte das interpretações de Cremilde Rosado Fernandes, artista estilística e virtuosisticamente afeiçoada ao gênero e, bem assim, ao autor, é a comoçào de se estar a ouvir velhas sonoridades e captar, dum mundo desaparecido e distante, graças à conjugação 


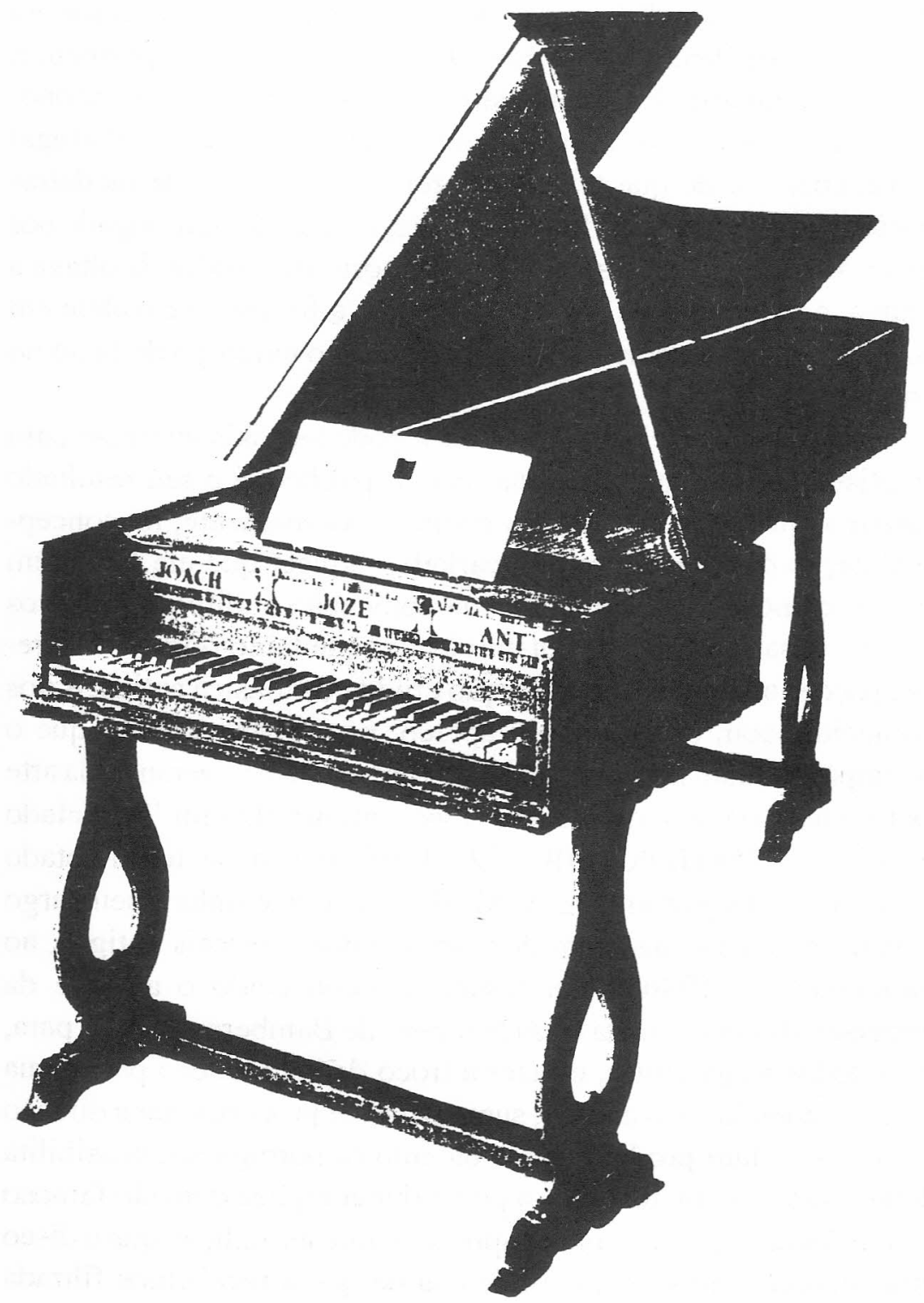

Cravo português de Joaquim José Antunes (Lisboa,1758) Gravura do estudo de G.Doderer in Libro di Tocate per Cembalo (...), de Domenico Scarlatti (Lisboa, INIC, 1991) 
do espírito scarlattiano e da alma do instrumento, essa "imagem sonora - a que se refere Doderer - que marca de forma pastosa o espectro melódico, num conjunto de linhas opulentas e "aromáticas".

Humberto d'Ávila, Musicólogo e investigador. Fundador da Juventude Musical Portuguesa. Antigo diretor do Departamento de Musicologia do Instituto Português do Património Cultural. Presidente da Assembleia Geral do Conselho Português da Música. 